\title{
Processamento bilíngue e interferências do português (L1) na produção escrita em inglês (L2): indícios em estudos de caso
}

PALAVRAS-CHAVE:

Psicolinguística do bilinguismo • Processamento bilíngue • Não-seletividade • Competição lexical • Interferências linguísticas

Daniele Aride

RESUMO: A Psicolinguística do Bilinguismo entende o processamento bilíngue como um fenômeno predominantemente não-seletivo (COSTA, 2005; LA HEIJ, 2006; GROSJEAN, 2012; FINGER e PREUSS, 2018), pelo qual dois sistemas linguísticos são ativados em paralelo, cabendo ao falante recuperar as informações corretas em seu léxico mental. De acordo com os autores, a múltipla ativação gera competição entre os itens, permitindo interferências de uma língua na outra. Partindo dessa premissa, o presente trabalho de caráter exploratório tem como objetivo fornecer indícios que contribuam para o debate dessa hipótese. Para tanto, foram examinadas produções escritas espontâneas de dois grupos de bilíngues brasileiros (português-inglês) com diferentes níveis de conhecimento do idioma-alvo (incipiente e produtivo). Após a análise e categorização dos dados, observamos que existem aspectos semânticos, sintáticos, morfológicos e ortográficos que apontam na direção da seleção competitiva, sendo igualmente possível que outros fatores, como o grau de proficiência na língua estrangeira, sejam capazes de influenciar a intensidade da ativação. 
WARREN, Paul. Introducing Psycholinguistics. Cambridge: Cambridge University Press, 2013.

\section{INTRODUÇÃO}

Indivíduos saudáveis possuem capacidade de armazenamento de informações admirável. Para que se tenha uma ideia, estudos feitos com falantes nativos de inglês estimam que os seres humanos guardam em seu léxico mental cerca de 20.000 palavras (WARREN, 2013). No curso da história, exemplos de pessoas que se destacam por sua memória prodigiosa não faltam. Conta-se, por exemplo, que Alexandre, o Grande, foi capaz de se lembrar dos nomes de todos os seus milhares de soldados. Mozart pôde reproduzir uma melodia que escutou uma única vez. D. Pedro II falava 23 idiomas, sendo fluente em 17. Winston Churchill sabia de cor quase todos os trabalhos de Shakespeare. Bill Gates, por sua vez, memorizou centenas de códigos de programação projetados por ele ${ }^{1}$.

Sabe-se que a habilidade de reter mais ou menos dados varia conforme o indivíduo, além de estar sujeita a diversos fatores, como o envelhecimento e o cansaço; mas não se pode negar ou desconsiderar o alto rendimento de nosso aparato mental. Diante dessa constatação, a Psicolinguística, área do conhecimento interdisciplinar que se ocupa dos processos subjacentes à aquisição, compreensão e produção da linguagem, é responsável por investigar, a partir de metodologias experimentais, os fenômenos cognitivos que explicam como informações linguísticas são organizadas mentalmente e, posteriormente, recuperadas pelo falante.

No que diz respeito especificamente ao processamento da língua materna (doravante L1) por adultos, as etapas envolvidas compreendem a produção e a compreensão da linguagem. Em se tratando de indivíduos bilíngues, no entanto, pode ser que a fase de aquisição de uma língua estrangeira (doravante L2) ainda esteja em andamento, ocorrendo de forma simultânea à produção e compreensão, especialmente se estivermos diante de um processo de aprendizagem tardio. Contudo, quando desconsideramos o fenômeno da aquisição e voltamo-nos inicialmente ao cenário monolíngue, em linhas gerais, entende-se a produção como um processo de codificação, ao passo que a compreensão é composta por uma decodificação.

1. A exploração da maioria desses exemplos pode ser encontrada em: https://www.learning-mind.com/interesting-facts-about-humanmemory/. 
LEVELT, W. Speaking: From Intention to Articulation. Massachusetts: Massachusetts Institute of Technology, 1989.

LEVELT, W. Models of word production. Trends in Cognitive Sciences. New York, v.3, n.6, p. 223232, jun. 1999.

FERNÁNDEZ, E.M.; CAIRNS, H.S. Fundamentals of Psycholinguistics. New Jersey: Wiley-Blackwell, 2011.
Enquanto codificação, a produção inclui um primeiro nível conhecido como conceptualização da mensagem (LEVELT, 1989, 1999). Trata-se de uma instância que antecede a linguagem propriamente dita, em que o falante elabora uma ideia abstrata do que pretende dizer, sem que ocorra a geração de palavras ou de sentenças para expressá-la. Tal elaboração preliminar é moldada tanto pela intenção dos indivíduos para atingir um objetivo comunicativo, como pelo contexto situacional, em que se elabora detalhadamente cada ato de fala. Assim, compreende dois momentos: o planejamento macro e o planejamento micro, respectivamente. $\mathrm{O}$ produto deste estágio é chamado de mensagem pré-verbal.

No nível seguinte à conceptualização, Levelt afirma que o input recebido passa por um processo de formulação, em que se transforma a estrutura conceptual em uma estrutura linguística. Nesse sentido, primeiro tem-se uma etapa de codificação gramatical, composta pelo processamento funcional - seleção lexical (lemas) e atribuição de função -, e pelo processamento posicional, em que os lemas selecionados são organizados em uma cadeia ordenada. Finda a codificação gramatical, passase à codificação morfofonológica, em que se atribui informações de natureza morfológica e fonológica a fim de se definir as formas das palavras (lexemas). $O$ resultado desse processo é a construção de um plano articulatório: uma representação interna de como o enunciado planejado deve ser articulado.

Por outro lado, o processo de compreensão envolve uma segmentação do continuum da fala para a sua decodificação (FERNÁNDEZ e CAIRNS, 2011). Praticamente espelhando a tarefa do falante na produção, o ouvinte primeiramente reconstrói a representação fonológica a partir de informações acústicas. Em seguida, utiliza a informação fonológica para recuperar os itens lexicais correspondentes em seu dicionário mental, resgatando as informações semânticas e estruturais das palavras usadas na mensagem e, por fim, constrói a representação sintática da sentença para estabelecer seu significado com o auxílio dos mecanismos de parsing 2 .

2. Para obter mais detalhes sobre o processo de compreensão e o funcionamento do parser, conferir os trabalhos de Fernández e Cairns (2011) e Warren (2013). 
GROSJEAN, F. Speech Production. In: GROSJEAN, F; LI, P. (Org.). The Psycholinguistics of Bilingualism. New Jersey: Wiley-Blackwell, 2012.
Por sua vez, quando se considera o contexto do bilinguismo ${ }^{3}$, como a etapa de aquisição de uma L2 pode ainda estar em curso paralelamente aos processos de produção e de compreensão, há a necessidade de um recorte mais amplo na análise de desempenho linguístico de indivíduos bilíngues. Sobretudo porque, quando a L2 é adquirida na fase adulta, é provável que os enunciados produzidos a partir das intenções comunicativas desses falantes revelem indícios de interferência da L1 na realização da L2, gerando interposições que podem ir desde a conceptualização da mensagem até a concretização do plano articulatório ou, de modo análogo, permear o processo de decodificação.

A fim de explorar o modo como o processamento bilíngue adulto se concretiza e as possíveis interseções entre L1 e L2, manifestadas, especialmente, em um processo de aquisição de língua estrangeira tardio, o objetivo deste trabalho é discutir os mecanismos de seleção lexical empregados pelos bilíngues e oferecer indícios de sobreposição observados na produção escrita espontânea de falantes do português (L1) e do inglês (L2). Para tanto, serão examinados textos produzidos por dois grupos de estudantes brasileiros bilíngues para fins de comparação: um grupo cuja proficiência na L2 é incipiente e outro cujo domínio é mais apurado. Dessa forma, pretende-se verificar se falantes bilíngues podem ser mais ou menos suscetíveis ao fenômeno da não-seletividade (GROSJEAN, 2012) dependendo do grau de proficiência em questão, algo que poderia vir a estimular experimentos na área da Psicolinguística do Bilinguismo, campo a ser abordado na próxima seção, em que se discute os diferentes sentidos de falante bilíngue.

\section{VISÕES DE BILINGUISMO}

O fenômeno do bilinguismo é amplamente percebido em todas as sociedades, mesmo naquelas em que se preconiza o imperativo monolíngue. Embora não seja possível afirmar quantas pessoas se comunicam em mais de um idioma e com que frequência isso é feito, no Brasil, por exemplo, país que possui duas línguas oficiais

3. Neste trabalho, entendemos como bilinguismo a capacidade de uso de dois sistemas linguísticos. 
FINGER, I.; PREUSS, E. A Psicolinguística do Bilinguismo: estudando 0 processamento linguístico e cognitivo bilíngue. In: FINGER, I.; PREUSS, E. (Org.). Dinâmica do processamento bilíngue. Campinas: Pontes Editores, 2018.

SAER, D. The effect of bilingualism on intelligence. [s. 1.], 1923.

BLOOMFIELD, L. Language. New York: Holt, Rinehart and Winston, 1933.
- o português e a LIBRAS ${ }^{4}$ - é comum encontrar pessoas que utilizam línguas estrangeiras em sua vida cotidiana, seja no âmbito pessoal ou profissional, como atividademeio ou atividade-fim. Nesse contexto, a subárea da Psicolinguística do Bilinguismo surge com o objetivo de investigar o modo como indivíduos aprendem e empregam as línguas que dominam, examinando os processos linguísticos e cognitivos subjacentes à aquisição e ao uso da linguagem por esses falantes (FINGER e PREUSS, 2018).

De modo a compreender melhor o objeto de estudo da Psicolinguística do Bilinguismo, cabe discutir, em primeiro lugar, as concepções de indivíduos bilíngues existentes na literatura. Nesse sentido, uma das primeiras definições de que se tem registro é a apresentada por Saer (1923), que defendeu a Hipótese do Duplo Monolíngue. Segundo essa concepção, haveria dois monolíngues em um mesmo indivíduo. Mais tarde, Bloomfield (1933) advogou a ideia de que o bilíngue é aquele que possui a fluência nativa de duas línguas. Tais visões tradicionais apresentadas pelos dois teóricos impõem a noção de perfeição ao bilinguismo, pois o falante bilíngue seria aquele que teria um desempenho idêntico ao de monolíngues no que diz respeito ao grau de proficiência.

Em uma perspectiva contemporânea, no entanto, a ideia de perfeição deixou de ser fundamental ao conceito de bilinguismo. Prevalece o entendimento de que o propósito do falante, o contexto e a função aplicada a uma determinada língua influenciam no que se concebe por indivíduo bilíngue. Assim, Finger e Preuss (2018) recorrem a Baker (2006) e Grosjean (2006) para argumentar que diversos fatores estão em jogo na descrição e caracterização de bilíngues, como: contextos de uso, nível de domínio, idade inicial de aprendizagem, status das línguas, nível de estabilidade de cada língua, tempo e forma de atuação em cada um dos sistemas linguísticos, dentre outros.

Ainda que não seja fácil definir bilinguismo, o consenso que se tem hoje é de que os bilíngues "se deslocam num continuum que abrange diferentes níveis de conhecimento lexical, proficiência e modos de atuação (monolínguebilíngue)" (FINGER e PREUSS, 2018, p.5). Com o intuito de sintetizar critérios que estabeleçam os diferentes tipos de falantes bilíngues, Finger e Preuss se voltam

4. Língua Brasileira de Sinais. 
para as análises de Wei (2000) e Butler e Hakuta (2006) e apresentam um quadro resumido com quatro aspectos principais a partir dos quais se estipula os diferentes tipos de bilinguismo. São eles: idade, contexto de aquisição, Em relação à idade de aquisição da L2, as autoras identificam quatro modalidades de bilíngues: precoce (entre 0 e 12 anos de idade), tardio (após os 12 anos de idade), simultâneo (aquisição das duas línguas desde o nascimento) e sucessivo (aquisição de uma língua após a outra). Quanto ao contexto de aquisição, este poderia ser composto, em que há aquisição simultânea das duas línguas e, muitas vezes, no mesmo contexto; ou coordenado, quando a aquisição se dá em contextos separados. No que diz respeito ao grau de uso das línguas, a classificação é em dominante, pelo qual há um alto nível de uso e de proficiência em uma das línguas; ou recessivo, quando há dificuldade de compreensão numa determinada língua, devido à baixa frequência de uso. Por fim, o nível de conhecimento das línguas pode ser produtivo (domínio da produção oral ou escrita nas duas línguas), receptivo (domínio da compreensão oral ou escrita nas duas línguas) ou incipiente (bilinguismo em fase inicial, pois uma das línguas ainda está em fase de desenvolvimento).

Tendo como referência o panorama disponibilizado pelas autoras para a conceitualização de bilinguismo, as escritas analisadas mais adiante neste trabalho terão como fonte dois grupos de aprendizes brasileiros de inglês que se enquadram nas seguintes categorias: um grupo 1, composto de estudantes adultos com perfil de aquisição tardio, sucessivo, coordenado, recessivo e incipiente; e um grupo 2, que integra alunos que diferem da descrição anterior apenas em relação ao nível de conhecimento linguístico, isto é, são indivíduos bilíngues produtivos. Nesses termos, no próximo item, começamos a abordar os fundamentos do processamento bilíngue, que servirão de base para nossa análise dos casos apresentados.

\section{PROCESSAMENTO BILÍNGUE}

Uma vez apresentadas as diferentes concepções de bilinguismo e o contexto de análise, passa-se à discussão do objeto de investigação da Psicolinguística do Bilinguismo, qual seja, o modo como o processamento bilíngue se opera. Considerando especificamente o escopo deste trabalho, considerar-se-á a particularidade do processo de produção bilíngue. Nesse sentido, Grosjean (2012) estabelece que o desenvolvimento de um modelo de produção para o bilinguismo deve levar em consideração, primeiramente, os diferentes modi operandi $i^{5}$ dos bilíngues, isto é, o modo monolíngue, contexto em que o bilíngue se comunica com alguém que só conhece uma das línguas envolvidas, e o modo bilíngue, em que os

5. Em outras palavras, os diferentes perfis de atuação. 
COSTA, A. Lexical Access in Bilingual Production. In: KROLL, J. F.; GROOT, A. M. B. de. (Ed.). Handbook of bilingualism: Psycholinguistic Approaches. Oxford: Oxford University Press, 2005. p. 308-325. interlocutores são proficientes nos dois idiomas. Nesse último cenário, o fenômeno de code-switching ${ }^{6}$ e a ocorrência de interferências entre os sistemas é bastante comum.

Grosjean acrescenta que no estudo da produção bilíngue um grande questionamento se coloca: a produção da linguagem se dá de forma seletiva ou não-seletiva? No caso de o processo ser seletivo, apenas a língua-alvo é ativada na situação comunicativa. Por outro lado, quando o mecanismo é não-seletivo, outra língua, além da língua-alvo, também entra em cena. Assim, podemos nos perguntar, será que a escolha lexical se dá entre todas as palavras ativadas nos dois sistemas, ou apenas a partir daquelas ativadas na língua-alvo?

$\mathrm{Na}$ literatura, pontos de vista contrastantes com base em experimentos conduzidos no tema almejaram elucidar essa questão. Não se chegou até o momento a uma resposta contundente, mas Finger e Preuss (2018) entendem que há um consenso na área de que os dois sistemas linguísticos do bilíngue são ativados em paralelo, independentemente de qual seria a língua-alvo, o que permite a competição entre os itens lexicais. Assim, o bilíngue português-inglês ao pensar em "cabeça", ativa também "head" "headache", "hair", além de outras palavras relacionadas na L2, como "dead", "toothache", "fair", dentre outras, já que existem inter-relações nas representações mentais nos três níveis de codificação da mensagem no processo de produção. Costa (2005) acrescenta, ainda, que a ativação se relaciona com a disponibilidade de determinada representação em cada nível, ou seja, quanto mais disponível, maior é o grau de ativação.

Experimentos realizados no estudo da seleção lexical por bilíngues incluem tarefas que medem os tempos de reação desses falantes diante de estímulos. É o caso, por exemplo, da nomeação de desenhos, em que o indivíduo escuta palavras-alvo e palavras-controle, e deve fazer a associação correta à imagem exibida. O procedimento permite avaliar efeitos de interferência interlinguística (semântica, de identidade, fonológica/ortográfica). Finger e Preuss apontam que "nos estudos em que se observa diferença nos tempos de reação entre palavras-alvo e palavras-controle e, a latência de nomeação das palavras-

6. Refere-se a alternância entre línguas no mesmo contexto discursivo. 
LA HEIJ, W. Selection Processes in Monolingual and Bilingual Lexical Access. In: KROLL, J. F. GROOT, A. M. B. de. (Ed.). Handbook of bilingualism: Psycholinguistic Approaches. Oxford: Oxford University Press, 2005. p. 289-307. alvo é menor, esse resultado é visto como indicação de que há competição entre as línguas" (FINGER e PREUSS, 2018, p.8). Por outro lado, quando se verifica que o tempo de reação é menor nas palavras-alvo, considera-se que a seleção é específica na língua. Contudo, questiona-se a precisão dessas pesquisas que atestam a seletividade e/ ou a não-seletividade no acesso lexical. Em que pese a evidência da múltipla ativação, o controle experimental empregado, às vezes, acaba por induzir uma dupla ativação na produção. Assim, Ortiz-Preuss (2018) sugere que certos fatores sejam monitorados com atenção em ambientes de testes, como o status cognato das palavras selecionadas e a frequência com que elas aparecem no léxico.

Postula La Heij (2005) que a escolha da língua a ser desempenhada ocorre na fase de conceptualização, e que os itens lexicais das duas línguas são agrupados em um único dicionário mental, o qual é composto de subconjuntos que organizam os elementos de cada língua. Nessa esteira, os indivíduos bilíngues precisam gerenciar os dois sistemas linguísticos para utilizar apenas um deles em uma situação comunicativa sem que haja interferências da outra língua. O mecanismo, a princípio, parece simples e coordenado, mas ainda não se sabe como o aparato mental trabalha para selecionar a palavra-alvo e inibir as demais em competição. Diante disso, passou-se a considerar também o papel das funções executivas (doravante FE) nessa empreitada, somando-se o processamento cognitivo ao linguístico.

Finger e Preuss definem as FE como os "processos cognitivos superiores de controle e integração para desempenhar um determinado comportamento e alcançar um objetivo" (FINGER e PREUSS, 2018, p.11). $\mathrm{O}$ processamento cognitivo, então, seria um dos responsáveis pelo êxito na seleção lexical, a partir do mecanismo de controle inibitório, mais apurado nos bilíngues altamente proficientes. Acrescentam as autoras que, no início do aprendizado de uma segunda língua, a demanda pelas FE é alta, a fim de que o indivíduo recupere fonemas e palavras e combine-os em estruturas. Com o tempo, certas práticas são aprimoradas e formas indesejadas são inibidas com mais facilidade, fazendo com que os processos se tornem automatizados e diminuindo a busca pelas FE. A esse respeito, reforça Costa (2005) que o aumento da proficiência na L2 promove uma troca, em que se recorre cada vez menos ao controle inibitório e mais ao mecanismo de seleção específica da língua. 
Por essa lógica, imagina-se que o grau de proficiência de indivíduos bilíngues afete os mecanismos de seleção lexical, ou seja, em um cenário cujos falantes são menos proficientes na L2, a seleção depende em maior nível de mecanismos de supressão da L1, ao passo que, em bilíngues mais proficientes na L2, espera-se que a seleção seja linguisticamente específica. Nesse prisma, na etapa seguinte, pretende-se averiguar se a produção escrita de aprendizes bilíngues (português-inglês) fornece subsídios que apontem em maior ou menor grau para a prevalência da seleção lexical competitiva ou específica, e se os dados de interferência diferem em quantidade/qualidade de acordo com o nível de proficiência dos falantes.

Aqui optamos pela modalidade escrita e em forma de "exercício para casa” a fim de reduzirmos a influência de fatores neuropsíquicos, como a pressa, o nervosismo e a ansiedade, os quais poderiam contaminar nossos resultados. Julgamos que a preferência pela oralidade poderia oferecer mais incertezas do que convicções quanto à existência de competição linguística, dada a sua natureza mais improvisada e menos automonitorada. Desse modo, o melhor controle das variáveis supracitadas e o maior planejamento discursivo fizeram com que a forma escrita se apresentasse como alternativa mais viável para investigar o processamento bilíngue nos termos desta pesquisa.

\section{ESTUDOS DE CASO}

Inicialmente, cumpre reforçar que o contexto considerado para o exame da produção escrita de bilíngues adultos falantes de português (L1) e inglês (L2) contemplou 12 (doze) indivíduos cujos perfis correspondem a graus de proficiência distintos: um grupo em nível elementar e um grupo em nível avançado de aprendizagem. Sendo assim, de acordo com a classificação proposta por Finger e Preuss (2018), se encaixam em incipientes - fase inicial de aquisição - e produtivos - domínio da produção nas duas línguas -, respectivamente.

Além disso, cabe ressaltar que a tarefa prescrita aos aprendizes compreendeu a redação de respostas a perguntas formuladas na L2. Para os alunos elementares, a proposta incluiu a escritura de frases curtas em inglês para perguntas objetivas, ao passo que os alunos avançados deviam elaborar textos de resposta mais aprimorados: seja com frases mais longas ou pequenas dissertações. Todo o direcionamento da atividade em questão foi feito na L2, o que poderia levar a crer que, em teoria, haveria a ativação apenas da língua-alvo, contudo, observou-se a manifestação de interferências da L1 nos dois grupos, revelando indícios de processamento em paralelo, o que será discutido nesta seção. 
MAIA, A. M. B. da. Os Erros de Interlíngua na Produção Escrita de LE (inglês): um estudo com alunos do ensino médio de uma escola pública do Distrito Federal. 2009. 111f. Dissertação (Mestrado em Linguística Aplicada). Departamento de Línguas Estrangeiras, Universidade de Brasília. Brasília, 2009.
Partindo desses cenários, a fim de classificar os resultados encontrados, a abordagem escolhida se baseou na categorização oferecida por Maia (2009) em sua Dissertação de Mestrado intitulada Os Erros de Interlíngua na Produção Escrita de LE (inglês): um estudo com alunos do ensino médio de uma escola pública do Distrito Federal. A autora usou como referência o tratamento dado por Lot (1983), que classifica os erros a partir dos componentes linguísticos semânticos, sintáticos, morfológicos e ortográficos, além do trabalho de Corder (1973), que agrupa os erros em três casos: omissão, adição e seleção de determinado item na construção de uma frase.

Às vistas disso, após a identificação das frases errôneas produzidas pelos bilíngues em comparação com a forma padrão vigente na língua inglesa (Standard American English), o procedimento adotado envolveu, primeiramente, a seleção dos erros que sugeriam a presença de interferências do português na L2. Em seguida, as estruturas coletadas foram organizadas individualmente de acordo com o nível linguístico a que pertenciam, bem como segundo o tipo de caso aplicável. Cada frase escolhida incluiu apenas uma ocorrência equivocada. Abaixo, temos a distribuição dos erros verificados em cada grupo bilíngue.

\section{- Erros no nível semântico:}

No nível semântico, os equívocos encontrados dizem respeito aos significados dos itens lexicais escolhidos pelos bilíngues para compor a estrutura oracional. Nesse sentido, a divisão foi feita em três categorias: seleção de um item incorreto, seleção de uma palavra da L1 e seleção sem distinção lexical. Segundo Maia (2009), a seleção de um item incorreto implica o uso de um sentido da L1 sob a forma inadequada de uma estrutura da L2. Por sua vez, a seleção de uma palavra da L1 corresponde à escolha de um item da língua materna por não se saber o termo correspondente na L2. Por fim, a seleção sem distinção lexical resulta no emprego inadequado, para o contexto de uso, de uma forma na L2. Assim, os erros encontrados foram os seguintes: 


\section{Grupo 1: aprendizes incipientes}

\section{Seleção de um item incorreto:}

1. I sometimes forget to give an information. (alvo: some) - Em português: Eu, às vezes, me esqueço de dar uma informação.

2. The sign says it has restrooms on the right. (alvo: there are) -Em português: $\mathrm{O}$ aviso diz que tem banheiros à direita.

Seleção de palavra da L1:

1. I went to France. (alvo: France) - Em português: Eu fui para a França.

Seleção sem distinção lexical:

1. I am doing a diet to lose some weight. (alvo: on) - Em português: Eu estou fazendo uma dieta para perder um pouco de peso.

2. I like to read, see series and play with my dogs. (alvo: watch) - Em português: Eu gosto de ler, ver séries e brincar com meus cachorros.

3. My house stays about 2 miles away from here. (alvo: is) - Em português: Minha casa fica a mais ou menos 3 quilômetros daqui.

4. I forgot my cellphone in the restroom. (alvo: I left) - Em português: Eu esqueci meu celular no banheiro.

5. When I was young my favorite toys were bears. (alvo: teddy bears) Em português: Quando eu era criança, meus brinquedos preferidos eram os ursos (de pelúcia).

6. Can I go to the roller coaster? (alvo: ride) - Em português: Posso ir na montanha-russa?

\section{Grupo 2: aprendizes produtivos}

Seleção de um item incorreto:

1. While the first ones think it is stupid to mix famous characters with ridiculous fantasy (...). (alvo: the former) - Em português: Enquanto os primeiros acham absurdo misturar personagens famosos com fantasia caricata (...).

2. Between the career and the experiences people have, should have a balance. (alvo: there should be) - Em português: Entre a carreira e as experiências que as pessoas têm, deveria ter um equilíbrio.

3. They went to an Indian restaurant to taste an exotic food. (alvo: some) - Em português: Eles foram para um restaurante indiano para experimentar uma comida exótica. 
Seleção sem distinção lexical:

1. Some of the important details the text uses are the gender of the film and the manipulation of people. (alvo: genre) - Em português: Alguns elementos importantes que o texto usa são o gênero do filme e a manipulação das pessoas.

2. They should always separate some time to do relaxing things. (alvo: spare) - Em português: Eles deviam sempre separar um tempo para fazer coisas relaxantes.

Mediante a comparação entre os dois grupos de bilíngues, se observa que, quanto à semântica, o grupo 1 foi o único a apresentar um caso de lapso de seleção de palavra da L1. Além disso, os equívocos envolvendo a distinção lexical foram os mais frequentes entre eles. Em contrapartida, o grupo 2 produziu menos erros em geral e foi mais equilibrado na distribuição dos desvios.

\section{- Erros no nível sintático:}

No aspecto sintático, os lapsos observados englobam a transferência de estruturas típicas do português para a produção em inglês. Neste ponto, cabe aqui uma consideração no que diz respeito ao tratamento do nível sintático, já que, neste trabalho, o foco repousa na competição lexical.

Embora os estudos de sintaxe tenham por base o componente estrutural, vimos que, para a Psicolinguística, a etapa de codificação gramatical é inicialmente composta pelo processamento funcional, momento em que ocorrem a seleção lexical e a atribuição de função. Somente após a sua conclusão é que se dá o processamento posicional, pelo qual os lemas recuperados são ordenados. Assim, entendemos que o exame do nível sintático se faz necessário pelo simples fato de que a escolha do léxico se dá em continuum com a disposição sintática. Por exemplo, só posso ordenar um complemento verbal (ex: objeto direto) se este já tiver sido previamente selecionado no léxico mental. Se isso não tiver ocorrido e/ ou se a ordenação se der de forma incorreta, temos indícios de que houve competição anterior.

Considerando esse entendimento, os exemplos produzidos foram elencados nas seguintes categorias, conforme Maia (Ibidem): omissão de preposição/pronome, uso incorreto de preposição/pronome, acréscimo de artigo e ordenação de itens. 


\section{Grupo 1: aprendizes incipientes}

\section{Omissão de pronome:}

1. I saw snow on my last vacation, and I loved. (alvo: loved it) - Em português: Eu vi neve nas minhas últimas férias e eu adorei $\underline{\emptyset}$.

2. It's ok because is my friend. (alvo: she/he) - Em português: Tudo bem porque é ø meu(minha) amigo(a).

Uso incorreto de preposição/pronome:

1. I don't mind with it. (alvo: I don't mind it) - Em português: Eu não me importo com isso.

2. My favorite toy was Barbie. I loved to play with her. (alvo: it) - Em português: Meu brinquedo preferido era a Barbie. Eu adorava brincar com ela.

3. Zack's Pharmacy opens every day at 6:30 of the morning. (alvo: in) Em português: Zack's Pharmacy abre todos os dias às 6 h30 da manhã.

4. I visited my mom in the last weekend. (alvo: last weekend) - Em português: Eu visitei minha mãe no fim de semana passado.

Acréscimo de artigo:

1. The (nome da escola) is just half mile away from my place. (alvo: nome

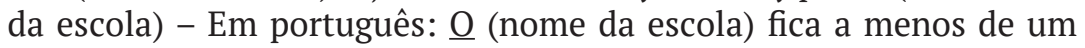
quilômetro da minha casa.

Ordenação de itens:

1. I had cheese and ham sandwich. (alvo: ham and cheese) - Em português: Eu comi um sanduíche de queijo e presunto.

\section{Grupo 2: aprendizes produtivos}

\section{Omissão de preposição/pronome:}

1. The guilty hasn't been identified yet. (alvo: The guilty one) - Em português: 0 culpado ainda não foi identificado.

2. He looked like was about to cry. (alvo: he was) - Em português: Ele parecia que $\emptyset$ estava prestes a chorar.

3. Jimmy, Cindy, Ernie and a friend of Cindy went to the driveway. (alvo: Cindy's) - Em português: Jimmy, Cindy, Ernie e um(a) amigo(a) da Cindy foram para a entrada da garagem.

4. Is a type of musical ensemble that usually consists of ten musicians. (alvo: it) -Em português: É um tipo de grupo musical que normalmente consiste em dez músicos. 
5. Freedom of speech is important because guarantees freedom of religion and freedom of peaceful assembly. (alvo: it) - Em português: Liberdade de expressão é importante porque ø garante a liberdade de culto e a liberdade de associação pacífica.

6. She didn't listen anything that her boyfriend said. (alvo: listen to) Em português: Ela não escutou nada que o namorado dela disse.

Uso incorreto de preposição/pronome:

1. Alice went to there. (alvo: went there) - Em português: Alice foi para lá.

2. Beating them and screaming with them. (alvo: at) - Em português: Espancando-os e gritando com eles.

3. When he got there, he saw she kissing someone. (alvo: her) - Em português: Quando ele chegou lá, ele viu “ela" beijando alguém.

4. She paid attention in every detail. (alvo: to) - Em português: Ela prestou atenção em todos os detalhes.

5. What would make me happier: spending some time with my family or working so hard? (alvo: Which) - O que me faria mais feliz: passar um tempo com minha família ou trabalhar duro?

Comparativamente, no que diz respeito à sintaxe, verificou-se que os aprendizes incipientes apresentaram indícios de interferências da L1 na L2 em todas as categorias, sendo que a maior incidência de lapsos envolveu o aspecto do uso incorreto de preposição/pronome. Já o grupo de aprendizes produtivos forneceu um número significativo de ocorrências tanto nos casos de omissão de preposição/pronome como em relação ao uso incorreto dessas classes gramaticais.

\section{Erros no nível morfológico:}

Em relação ao componente morfológico, os erros dos bilíngues se dão no nível da palavra, com o acréscimo ou a supressão de um morfema na produção escrita em inglês, a partir de regras do português.

\section{Grupo 1: aprendizes incipientes}

Acréscimo de morfema:

1. I can buy news books and games. (alvo: new) - Em português: Eu posso comprar livros e jogos novos.

2. I forget to give information to others people. (alvo: other) - Em português: Eu esqueço de dar informação a outras pessoas. 


\section{Grupo 2: aprendizes produtivos}

Acréscimo de morfema:

1. They also complement each other because of their differents types of views. (alvo: different)-Em português: Eles também se complementam por causa dos diferentes tipos de opinião.

Neste nível de representação, os lapsos encontrados nos dois grupos foram poucos e apenas na ordem do uso do morfema de plural na classe dos adjetivos. Isso se justifica pelo fato de que a língua inglesa possui poucas variações nessa instância: não há flexão de gênero e a flexão verbal é limitada. Como os resultados foram aproximados, não é possível afirmar que o grupo dos aprendizes incipientes tiveram desempenho significativamente inferior ao dos bilíngues produtivos em relação às interferências da L1 na L2.

\section{- Erros no nível ortográfico:}

Nesta esfera, há interferências entre os sistemas ortográficos da L1 e da L2, normalmente, influenciadas pela similaridade segmental fonológica. Assim, as formas encontradas foram organizadas da seguinte maneira: troca de grafema, omissão de grafema e acréscimo de grafema.

\section{Grupo 2: aprendizes produtivos}

\section{Troca de grafema:}

1. You have to work so you can have the essencial things you need. (alvo: essential) - Em português: Você tem que trabalhar para poder ter as coisas essenciais de que você precisa.

Omissão de grafema:

1. Cindy really thought about some of her atitudes. (alvo: attitudes) - Em português: Cindy refletiu de verdade sobre algumas de suas atitudes.

Acréscimo de grafema:

1. It's an original ideia and it's playful and creative. (alvo: idea) - Em português: É uma ideia original e é divertida e criativa.

2. The autor thinks it is just disrespectful to make a film about an important icon. (alvo: author) - Em português: $\mathrm{O}$ autor acha que é desrespeitoso fazer um filme sobre um ícone importante. 
Por fim, acerca do aspecto ortográfico, de maneira talvez surpreendente, observou-se que os falantes bilíngues do grupo 2 produziram lapsos na escrita envolvendo trocas, omissões e acréscimos de grafemas, ao passo que os bilíngues do grupo 1 não produziram erros dessa ordem.

\subsection{BREVES COMENTÁRIOS}

De modo geral, quando se consideram todos os níveis de representação linguísticos, nota-se que, em termos de quantidade, os bilíngues produtivos (grupo 2) apresentaram mais casos de interferência da L1 na L2 (21 ocorrências) do que os incipientes do grupo 1 (19 ocorrências), conforme se vê na figura 1 .

Figura 1
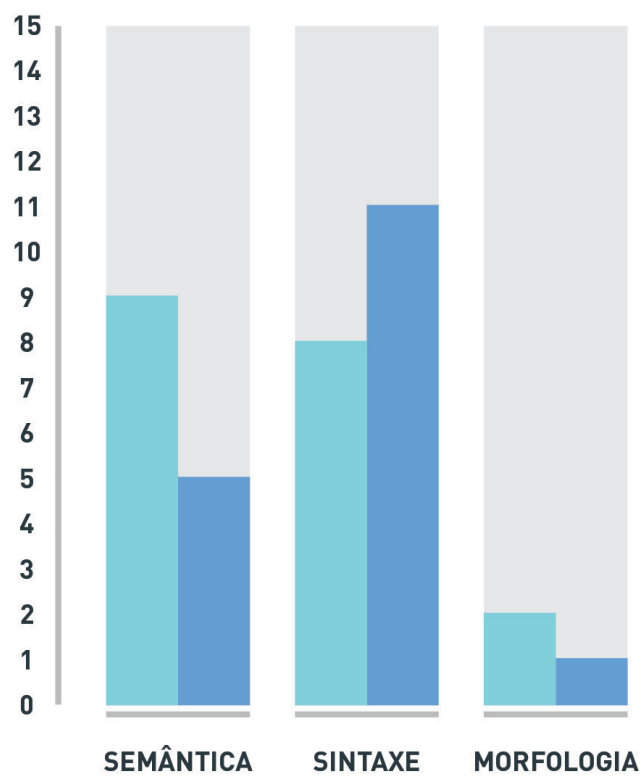

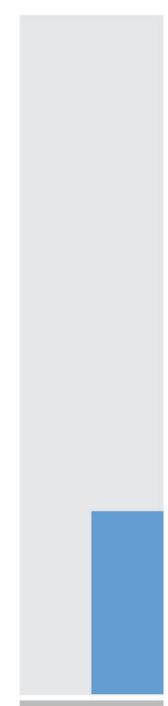

- Grupo 1 ( $\mathrm{T}=19)$

- Grupo $2(\mathrm{~T}=21)$

Fonte: a autora

Embora a diferença quantitativa entre os dois não seja propriamente significativa, isso pode ser explicado pelo fato de que os textos produzidos pelos falantes proficientes demandavam maior extensão, enquanto que os do grupo 1 eram notadamente mais curtos. Além disso, os temas desenvolvidos pelo grupo dos produtivos eram mais abrangentes e menos presos a contextos de sala de aula, o que pode ter influenciado nesse pequeno desequilíbrio. No mais, fatores como o cansaço, a pressa e a própria baixa frequência de uso individual podem ter igualmente acarretado tal descompasso. 
Cabe ressaltar, no entanto, que quando se analisam os tipos dos erros cometidos, percebe-se que o grupo dos bilíngues pouco proficientes foi o que produziu a maior variedade de casos de interferência nos níveis semântico e sintático. Vimos que tais camadas refletem a etapa chamada de formulação, primeiro momento de produção efetivamente linguística, em que a codificação gramatical se realiza. Nessa perspectiva, o grupo 1 produziu alguns erros distintos do grupo 2, que incluíram seleção de palavra na L1 (França no lugar de France), acréscimo de artigo (the) e ordenação de itens (cheese and ham). Além disso, a maioria dos desvios fornecidos pelos incipientes envolveu palavras de conteúdo (substantivos, verbos e adjetivos).

Enquanto isso, o grupo 2 foi mais equilibrado em termos de variação nos níveis semântico e sintático, mas produziu muitos desvios em relação à escolha dos pronomes e preposições (palavras de função), conforme mostramos na figura 2 .

Figura 2

\begin{tabular}{|c|c|c|c|c|c|c|}
\hline & VERBOS & SUBSTANTIVOS & ADJETIVOS & ARTIGOS & PRONOMES & PREPOSIÇÕES \\
\hline GRUPO 1 & 6 & 3 & 2 & 2 & 3 & 3 \\
\hline GRUPO 2 & 2 & 2 & 1 & 1 & 7 & 4 \\
\hline
\end{tabular}

Segundo Warren (2013), diferentemente das palavras de conteúdo, os elementos de função são resgatados em um segundo momento do processo de formulação, na fase de codificação morfofonológica, quando se atribui a forma e se elabora o plano articulatório. Assim, o resultado parece sugerir que os incipientes resgatam conceitos com interferências em um nível mais preliminar do que os produtivos, os quais apresentaram mais contato entre os dois sistemas linguísticos no âmbito formal.

Além disso, o grupo 2 gerou ocorrências mais variadas no nível ortográfico, incluindo trocas, adições e omissões de grafemas. Tais casos talvez sejam resultado de uma ausência de revisão, não sendo possível garantir que indicam falta de conhecimento das grafias dos itens lexicais na L2, caso em que o recurso à forma correspondente em português seria utilizado. Assim, se optamos por desconsiderar o componente ortográfico, o desempenho geral dos bilíngues incipientes é menos seletivo do que o dos bilíngues produtivos. É o que se observa na figura 3. 
Figura 3

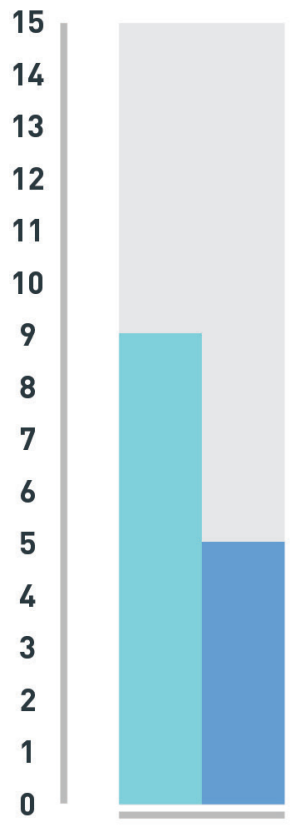

SEMÂNTICA

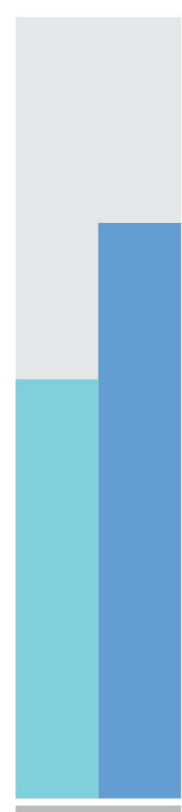

SINTAXE

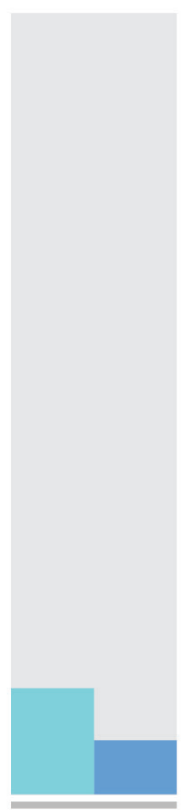

Grupo 1 ( $\mathrm{T}=19)$

Grupo 2 (T=17)

MORFOLOGIA
Fonte: a autora

\section{CONCLUSÃO}

Tendo em vista as categorizações oferecidas a partir das possibilidades de interferência da L1 na L2 encontradas no processo de produção de escrita espontânea por bilíngues proficientes e pouco proficientes e, considerando também o consenso na área da Psicolinguística do Bilinguismo, que entende que a ativação lexical no bilíngue se opera de forma não-seletiva, pode-se dizer que foram encontrados indícios que reforçam a ideia de que o processamento por esses indivíduos ocorre de forma paralela.

Além disso, é razoável também postular que o nível de conhecimento da língua-alvo pode influenciar na intensidade da ativação, sendo necessário que mais ou menos mecanismos inibitórios se apresentem a fim de minimizar a transposição da L1 para a L2, fazendo com que o bilíngue ignore determinados itens lexicais e restrinja a seleção. Isso foi percebido, por exemplo, no desempenho mais variado em termos de erros apresentados pelo grupo 1 em relação ao grupo 2, bem como na produção de lapsos envolvendo mais palavras de conteúdo - caso do grupo 1 -, do que de função, caso do grupo 2. 
Contudo, como o objetivo deste trabalho é exploratório, isto é, busca apenas revelar traços que sugerem interferências, não podemos afirmar que as ocorrências identificadas nas redações dos aprendizes atestam uma múltipla ativação e a competição entre os itens lexicais dos dois sistemas linguísticos, com influência dos diferentes graus de proficiência. Dessa forma, cabe à Psicolinguística, por meio dos métodos experimentais adequados, refutar ou confirmar essa hipótese de pesquisa, utilizando um design metodológico em que a co-ativação não seja induzida, e a amostra de participantes seja ampliada. Como verificamos diferenças de desempenho envolvendo palavras de conteúdo e de função, a conciliação das duas variáveis talvez seja uma opção relevante nesse tipo de estudo.

Assim, esperamos que este trabalho sirva de estímulo para os psicolinguistas do bilinguismo e ajude a lançar novos olhares sobre a matéria, especialmente em relação à produção escrita bilíngue sob a ótica cognitiva no contexto brasileiro, ainda pouco explorada na área, mas muito presente na vida dos aprendizes de línguas estrangeiras. 
Daniele Aride (daniele.aride@yahoo.com.br)

Mestranda do Programa de Pós-Graduação em Estudos da Linguagem da PUC-Rio.

\section{Como citar esse artigo}

ARIDE, Daniele. Processamento bilíngue e interferências do português (L1) na produção escrita em inglês (L2): indícios em estudos de caso. Revista Gatilho, UFJF, v. 18, p. 149-169. out. 2020.

\section{Bilingual processing and interference of Portuguese (L1) in the production of written texts in English (L2): evidence in case studies}

ABSTRACT: The Psycholinguistics of Bilingualism understands bilingual processing as a predominantly nonselective phenomenon (COSTA, 2005; LA HEIJ, 2006; GROSJEAN, 2012; FINGER and PREUSS, 2018), by which two linguistic systems are activated in parallel, and the speaker must retrieve the right information from their mental lexicon. According to the authors, multiple activation enables competition amongst items, allowing interference from one language into another. Based on this assumption, the present exploratory study aims at providing evidence that contributes to the debate of this hypothesis. For this purpose, spontaneous written texts produced by two Brazilian bilingual groups (Portuguese-English) with different degrees of expertise in the target language (incipient and productive) were examined. Following the analysis and categorization of data, we observed that there are semantic, syntactic, morphologic and orthographic aspects that point in the direction of competitive selection. It is equally possible that other elements, such as the proficiency level in a foreign language, be able to affect the strength of activation.

KEYWORDS: Psycholinguistics of bilingualism. Bilingual processing. Nonselectivity. Lexical competition. Linguistic interference. 


\section{REFERÊNCIAS:}

MAIA, A. M. B. da. Os Erros de Interlíngua na Produção Escrita de LE (inglês): um estudo com alunos do ensino médio de uma escola pública do Distrito Federal. 2009. 111f. Dissertação (Mestrado em Linguística Aplicada). Departamento de Línguas Estrangeiras, Universidade de Brasília. Brasília, 2009.

BLOOMFIELD, L. Language. New York: Holt, Rinehart and Winston, 1933.

COSTA, A. Lexical Access in Bilingual Production. In: KROLL, J. F.; GROOT, A. M. B. de. (Ed.). Handbook of bilingualism: Psycholinguistic Approaches. Oxford: Oxford University Press, 2005. p. 308-325.

FERNÁNDEZ, E.M.; CAIRNS, H.S. Fundamentals of Psycholinguistics. New Jersey: WileyBlackwell, 2011.

FINGER, I.; PREUSS, E. A Psicolinguística do Bilinguismo: estudando o processamento linguístico e cognitivo bilíngue. In: FINGER, I.; PREUSS, E. (Org.). Dinâmica do processamento bilíngue. Campinas: Pontes Editores, 2018.

GROSJEAN, F. Speech Production. In: GROSJEAN, F; LI, P. (Org.). The Psycholinguistics of Bilingualism. New Jersey: Wiley-Blackwell, 2012.

LA HEIJ, W. Selection Processes in Monolingual and Bilingual Lexical Access. In: KROLL, J. F. GROOT, A. M. B. de. (Ed.). Handbook of bilingualism: Psycholinguistic Approaches. Oxford: Oxford University Press, 2005. p. 289-307.

LEARNING MIND. Disponível em: <https://www.learning-mind.com/interesting-facts-abouthuman-memory/>. Acesso em: 15 jul. 2019.

LEVELT, W. Speaking: From Intention to Articulation. Massachusetts: Massachusetts Institute of Technology, 1989. jun. 1999.

. Models of word production. Trends in Cognitive Sciences. New York, v.3, n.6, p. 223-232,

ORTIZ-PREUSS, E. Produção de fala bilíngue: o processo de seleção lexical. In: FINGER, I.; PREUSS, E. (Org.). Dinâmica do processamento bilíngue. Campinas: Pontes Editores, 2018.

SAER, D. The effect of bilingualism on intelligence. [s. 1.], 1923. Disponível em: <http://search. ebscohost.com/login.aspx?direct=true \& db=edsbas \&AN=edsbas.309E08E6\&lang=pt-br \&site=edslive\&scope=site>. Acesso em: 15 jul. 2019.

WARREN, Paul. Introducing Psycholinguistics. Cambridge: Cambridge University Press, 2013. 